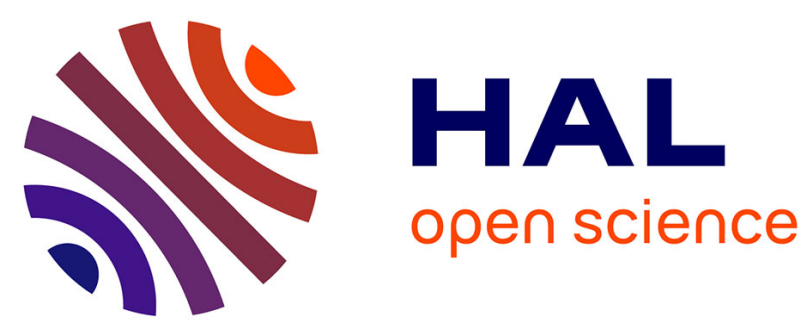

\title{
Sequential Barium-Catalysed N-H/H-Si Dehydrogenative Cross-Couplings: Cyclodisilazanes versus Linear Oligosilazanes
}

Clément Bellini, Thierry Roisnel, Jean-François Carpentier, Sven Tobisch, Yann Sarazin

\section{To cite this version:}

Clément Bellini, Thierry Roisnel, Jean-François Carpentier, Sven Tobisch, Yann Sarazin. Sequential Barium-Catalysed N-H/H-Si Dehydrogenative Cross-Couplings: Cyclodisilazanes versus Linear Oligosilazanes. Chemistry - A European Journal, 2016, 22 (44), pp.15733 - 15743. 10.1002/chem.201603191 . hal-01398042

HAL Id: hal-01398042

https://hal-univ-rennes1.archives-ouvertes.fr/hal-01398042

Submitted on 23 Feb 2017

HAL is a multi-disciplinary open access archive for the deposit and dissemination of scientific research documents, whether they are published or not. The documents may come from teaching and research institutions in France or abroad, or from public or private research centers.
L'archive ouverte pluridisciplinaire HAL, est destinée au dépôt et à la diffusion de documents scientifiques de niveau recherche, publiés ou non, émanant des établissements d'enseignement et de recherche français ou étrangers, des laboratoires publics ou privés. 


\title{
Sequential Barium-catalysed N-H/H-Si Dehydrogenative Cross-couplings:
}

\section{Cyclodisilazanes vsLinear Oligosilazanes}

\author{
Clément Bellini, ${ }^{[\mathrm{a}]}$ Thierry Roisnel, ${ }^{[\mathrm{b}]}$ Jean-François Carpentier, ${ }^{[\mathrm{a}]}$ \\ Sven Tobisch, ${ }^{[\mathrm{c}]}$ and Yann Sarazin ${ }^{[\mathrm{a}]}$
}

[a] Organometallics: Materials and CatalysisDepartment, Institut des Sciences Chimiques de Rennes, UMR 6226 CNRS - Université de Rennes 1, Campus de Beaulieu, F-35042 Rennes,France.

E-mail: jean-francois.carpentier@univ-rennes1.fr; yann.sarazin@univ-rennes1

${ }^{[b]}$ Centre de Diffractométrie des Rayons X, Institut des Sciences Chimiques de Rennes, UMR 6226 CNRS - Université de Rennes 1, F-35042, Rennes, France.

${ }^{[c]}$ University of St Andrews, School of Chemistry, Purdie Building, North Haugh, St Andrews KY16 9ST, United Kingdom. E-mail: st40@st-andrews.ac.uk

Keywords: $\mathrm{N}-\mathrm{H} / \mathrm{H}-\mathrm{Si}$ dehydrogenativecross-coupling • barium • silazanes $\bullet$ sequential chain extension $\bullet$ cyclisation

\section{Graphical Abstract}

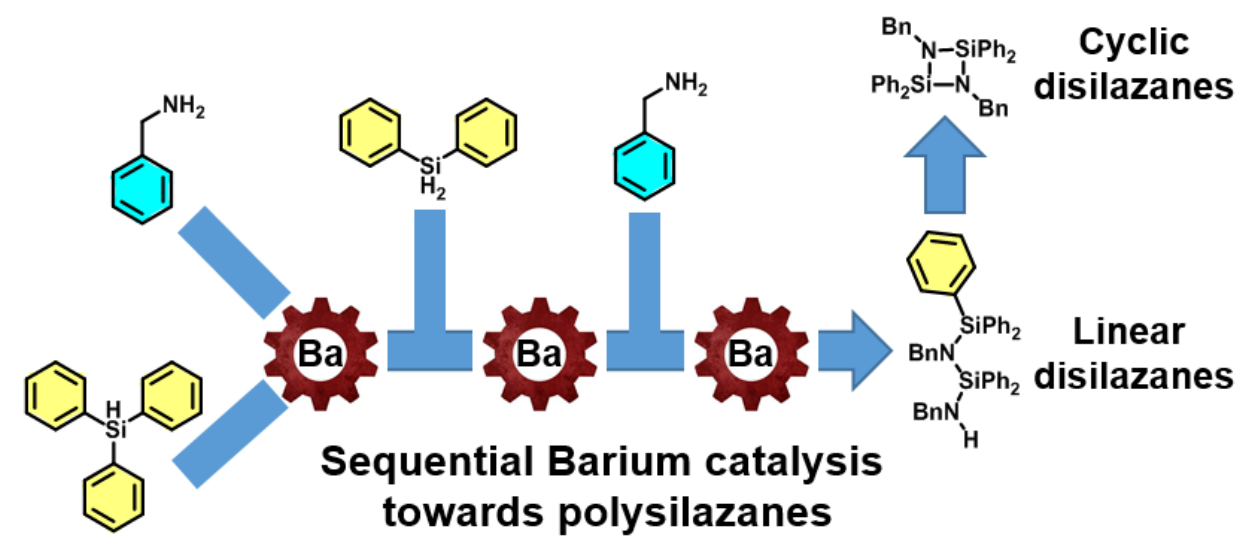




\begin{abstract}
Starting from $\mathrm{Ph}_{3} \mathrm{SiH}$, the barium precatalyst $\mathrm{Ba}\left[\mathrm{CH}\left(\mathrm{SiMe}_{3}\right)_{2}\right]_{2} \bullet(\mathrm{THF})_{3}$ was used to produce the disilazane $\mathrm{Ph}_{3} \mathrm{SiN}(\mathrm{Bn}) \mathrm{SiPh}_{2} \mathrm{NHBn}$ (4) by sequential $\mathrm{N}-\mathrm{H} / \mathrm{H}-\mathrm{Si}$ dehydrocouplings withBnNH $\mathrm{N}_{2}$ and $\mathrm{Ph}_{2} \mathrm{SiH}_{2}$. Substrate scope was extended to other amines and hydrosilanes. This smooth protocol gives quantitative yields and full chemoselectivity. Compound $\mathbf{4}$ and the intermediates $\mathrm{Ph}_{3} \mathrm{SiNHBn}$ and $\mathrm{Ph}_{3} \mathrm{SiN}(\mathrm{Bn}) \mathrm{SiHPh}_{2}$ were structurally characterised. Further attempts at chain extension by dehydrocoupling of $\mathrm{Ph}_{2} \mathrm{SiH}_{2}$ with 4 were metinstead by cyclisation of this compound, formingthe cyclodisilazane $c-\left(\mathrm{Ph}_{2} \mathrm{Si}-\mathrm{NBn}\right)_{2}$ (5) which was crystallographically authenticated. The ring-closure mechanism leading to5upon release of $\mathrm{C}_{6} \mathrm{H}_{6}$ wasdetermined by complementaryexperimental and theoretical (DFT) investigations. $\mathrm{Ba}\left[\mathrm{CH}\left(\mathrm{SiMe}_{3}\right)_{2}\right]_{2} \bullet(\mathrm{THF})_{3}$ and4react to affordthe reactiveBa $\left\{\mathrm{N}(\mathrm{Bn}) \mathrm{SiPh}_{2} \mathrm{~N}(\mathrm{Bn}) \mathrm{SiPh}_{3}\right\}_{2}$, which was characterised in situby NMR spectroscopy. Next, in a stepwise process, intramolecular nucleophilic attack of the metal-bound amide onto the terminal silicon atom generates a fivecoordinate silicate. It is followed by turnover-limiting $\mathrm{C}_{6} \mathrm{H}_{5}$-transfer to barium;this releases $\mathbf{5}$ and forms a transient $[\mathrm{Ba}]-\mathrm{Ph}$ species, which undergoes aminolysis to regenerate [Ba]$\mathrm{N}(\mathrm{Bn}) \mathrm{SiPh}_{2} \mathrm{~N}(\mathrm{Bn}) \mathrm{SiPh}_{3}$. DFT computations reveal that the irreversible production of 5 through suchastepwise ring-closure mechanismis much more kinetically facile $\left(\Delta G^{\ddagger}=26.2\right.$ $\left.\mathrm{kcal} \mathrm{mol}^{-1}\right)$ than analternative $\sigma$-metathesis pathway $\left(\Delta G^{\ddagger}=48.2 \mathrm{kcal} \mathrm{mol}^{-1}\right)$.
\end{abstract}




\section{Introduction}

Silazanes are common and versatile compounds containing $\mathrm{N}-\mathrm{Si}$ bonds whichcan be used in coordination chemistry, ${ }^{[1]}$ as bases,${ }^{[2]}$ silylating agents ${ }^{[3]}$ or protecting groups for amines, indoles and anilines in organic synthesis. ${ }^{[4]}$ Oligo- and polysilazanes are commonly prepared by alkali-mediated ring-opening polymerisation of cyclosilazanes following the SeyferthWiseman procedure. ${ }^{[5]}$ Although readily implemented, this oligo/polymerisation method necessitates the synthesis of cyclosilazanes which are not easily characterised.$^{[5,6]}$ Alternativeroutes to oligo- and polysilazanes involve the dehydrocouplingof amines and hydrosilanes, which can be catalysed by a variety of complexes of late transition metals ${ }^{[7]}$ or titanium, ${ }^{[8]}$ or the older polycondensation by ammonolysis and aminolysis reaction. ${ }^{[6 a, 9]}$ Polycarbosilazanes are related preceramics containing $-(\mathrm{Si}-\mathrm{C}-\mathrm{N})_{n}-$ backbones; amorphous SiCN ceramics are useful for their corrosion resistance, high-temperature stability, and long-term durability for applications as structural materials. ${ }^{[10]}$ Polycarbosilazanes are commonly synthesised by aminolysis of dichlorosilanes with 1,2 -ethylenediamine ${ }^{[11]}$ or other diamines ${ }^{[12]}$ upon release of ammonium chlorides as by-products. Original dendrimers were obtained in an iterative two-step strategy employing first Karstedt's catalyst for the hydrosilylation of tris(vinyldimethylsilyl)amine with chlorodimethylsilane, followed by treatment with alkali bis(vinyldimethylsilyl)amide. ${ }^{[13]}$ Nevertheless, until recently the most atom-efficient synthetic protocol relied on the cross-dehydrocoupling (CDC) of 1,4bis(dimethylsilyl)benzene and ammonia catalysed by $\mathrm{Pd}_{2}(\mathrm{dba})_{3}$, an attractive process even though the reaction requires $72 \mathrm{~h}$ to convert parts only of 200 equiv of the comonomers. ${ }^{[14]}$

We have been keen on implementing alkaline earth complexes $(\mathrm{Ae}=\mathrm{Ca}, \mathrm{Sr}, \mathrm{Ba})$ in catalysed $\mathrm{N}-\mathrm{H} / \mathrm{H}-\mathrm{Si}$ dehydrocoupling reactions, a clean route to the production of silazanes ${ }^{[15]}$ and polycarbosilazanes. ${ }^{[16]}$ We have shown that barium precatalysts display a unique combination of high activity and chemoselectivity in the couplings of a variety of 
amines, (di)hydrosilanes, $\alpha, \omega$-diamines and $\alpha, \omega$-di(hydrosilane)s, which has enabled access to a range of silazanes and linear disilazanes. Other catalytic systems exist for this type of reactions. Some are built on middle and late transition metals, e.g. $\mathrm{Al}_{2} \mathrm{O}_{3}$-supported palladium species and graphene-supported palladium nanoparticles, ${ }^{[17]} \mathrm{Ru}_{3}(\mathrm{CO})_{12}$ and $\mathrm{Rh}_{6}(\mathrm{CO})_{16}$ clusters, ${ }^{[7 \mathrm{a}-\mathrm{b}, 18]}$ as well as discrete ruthenium, ${ }^{[4 \mathrm{~b}, 4 \mathrm{e}]}$ rhodium, ${ }^{[4 \mathrm{c}, 7 \mathrm{c}]}$ chromium ${ }^{[19]}$ or copper complexes. ${ }^{[20]}$ Precatalysts based onoxophilic metals such as titanium,,${ }^{[8,21]}$ aluminium, ${ }^{[22]}$ yttrium, ${ }^{[23]}$ ytterbium(II),${ }^{[24]}$ uranium(IV $),{ }^{[25]}$ zinc, ${ }^{[26]}$ alkali metals ${ }^{[27]}$ and alkalineearths, ${ }^{[15,28]}$ for which $\sigma$-bond metathesis or Si-to-metal $\beta$-hydride transfer are key mechanistic features, have proved very effective of late.

We report here on the utilisation of $\mathrm{Ba}\left[\mathrm{CH}\left(\mathrm{SiMe}_{3}\right)_{2}\right]_{2} \bullet(\mathrm{THF})_{3}$, a most efficient bariumbased precatalyst for $\mathrm{N}-\mathrm{H} / \mathrm{H}-\mathrm{Si}$ dehydrocouplings, ${ }^{[15]}$ for the preparation of original compounds containing several silazanyl linkers. They are obtained by a controlled extension process upon sequential coupling of a variety dihydrosilazanes and diamines. It is shown how the same precatalyst can also readily lead to the ring-closing formation of 4-member cyclodisilazanes. The results of DFT computations aimed at probing the rival mechanistic pathways leading to cyclisation are presented. 


\section{Results and Discussion}

\section{Initial reactivity studies}

The barium precatalystBa[CH$\left.\left(\mathrm{SiMe}_{3}\right)_{2}\right]_{2} \bullet(\mathrm{THF})_{3}$ (A), which has recently proved very effective in $\mathrm{N}-\mathrm{H} / \mathrm{H}-\mathrm{Si}$ CDC reactions, ${ }^{[15,16]}$ was selected in the present study. Itcatalyses the coupling of triphenylsilane and benzylamine $\left(\left[\mathrm{Ph}_{3} \mathrm{SiH}\right]_{0} /\left[\mathrm{BnNH}_{2}\right]_{0} /[\mathbf{A}]_{0}=400: 400: 1\right.$, $\left[\mathrm{BnNH}_{2}\right]_{0}=4.0 \mathrm{M}$ in benzene)at $25{ }^{\circ} \mathrm{C}$ within $2 \mathrm{~h}$ to afford the known monocoupled product $\mathrm{Ph}_{3}$ SiNHBn (1) with entire chemoselectivity.Singlecrystals of $\mathbf{1}$, the starting material for the subsequent work described here, were obtained and its molecular solid-state structure was established. Under these experimental conditions, the formation of the dicoupled product, $\mathrm{Ph}_{3} \mathrm{SiN}(\mathrm{Bn})_{2}$ (2), or that of cyclic disilazanes were not detected. Compound 2 could only be obtained in poor yields by coupling of $\mathrm{Ph}_{3} \mathrm{SiH}$ with pre-isolated $\mathbf{1}\left(12 \mathrm{~h}, 25^{\circ} \mathrm{C}\right.$, yield: $15 \% ; 60{ }^{\circ} \mathrm{C}$, yield:22\%); high precatalyst loading had to beused, typically $\left[\mathrm{Ph}_{3} \mathrm{SiH}\right]_{0} /[\mathbf{1}]_{0} /[\mathbf{A}]_{0}$ $=20: 20: 1$, with $[\mathbf{1}]_{0}=0.20 \mathrm{M}$ in benzene (Scheme 1). ${ }^{[29]}$ The difficulties encounteredin obtaining 2 are reminiscent of the little propensity shown by $\mathrm{R}_{3} \operatorname{SiNHR}$ ' silazanes $\left(\mathrm{R}, \mathrm{R}^{\prime}=\right.$ aryl, alkyl) to engage in Ae-mediated cross-dehydrocoupling reactions with bulky hydrosilanes such as $\mathrm{Ph}_{3} \mathrm{SiH}$, and can probably be ascribed to excessive steric congestion. ${ }^{[15]}$

Scheme 1.Synthesis of $\mathrm{Ph}_{3} \mathrm{SiNHCH}_{2} \mathrm{C}_{6} \mathrm{H}_{5}(\mathbf{1})$ catalysed by $\mathrm{Ba}\left[\mathrm{CH}\left(\mathrm{SiMe}_{3}\right)_{2}\right]_{2} \bullet(\mathrm{THF})_{3}(\mathbf{A}){ }^{[29]}$ 
With a less cumbersome andmore reactivehydrosilane,the coupling of high loadings of 1 with diphenylsilane $\left(\equiv \mathrm{Ph}_{2} \mathrm{SiH}_{2}\right)$ catalysed by $\mathbf{A}\left(\left[\mathrm{Ph}_{2} \mathrm{SiH}_{2}\right]_{0} /[\mathbf{1}]_{0} /[\mathbf{A}]_{0}=400: 400: 1,[\mathbf{1}]_{0}=\right.$ 4.00 $\mathrm{M}$ in benzene) was quantitative within $2 \mathrm{~h}$ at $25{ }^{\circ} \mathrm{C}$ and afforded the asymmetric disilazane $\mathrm{Ph}_{3} \mathrm{SiN}(\mathrm{Bn}) \mathrm{SiHPh}_{2}$ (3) with entire selectivity(Scheme 2). This compound was isolated and dehydrocoupled with $\mathrm{BnNH}_{2}\left([\mathbf{3}]_{0} /\left[\mathrm{BnNH}_{2}\right]_{0} /[\mathbf{A}]_{0}=100: 100: 1,\left[\mathrm{BnNH}_{2}\right]_{0}=1.0\right.$ $\mathrm{M}$ in benzene)at $60{ }^{\circ} \mathrm{C}$ within $2 \mathrm{~h}$, to give the linear product $\mathrm{Ph}_{3} \mathrm{SiN}(\mathrm{Bn}) \mathrm{SiPh}_{2} \mathrm{NHBn}_{\text {(4) }}$ quantitatively. See the Supporting Information for complete product characterisation.

Scheme 2. Stepwise syntheses of silazanes and (cyclo-)disilazanes catalysed by $\mathrm{Ba}\left[\mathrm{CH}\left(\mathrm{SiMe}_{3}\right)_{2}\right]_{2} \bullet(\mathrm{THF})_{3}(\mathbf{A})$. All reactions were carried out in benzene. ${ }^{[29]}$

We tried to extend this stepwise chain growth to the production of longer molecules with the ambition to obtain oligo- and, ultimately, polycarbosilazanes.However, the attempted coupling of 4 with $\mathrm{Ph}_{2} \mathrm{SiH}_{2}(0.2 \mathrm{M}$ for each substrate $)$ did not yield the expected $\mathrm{Ph}_{3} \mathrm{SiN}(\mathrm{Bn}) \mathrm{SiPh}_{2} \mathrm{~N}(\mathrm{Bn}) \mathrm{SiPh}_{2} \mathrm{H}$, but instead returned quantitativelythe cyclodisilazane $c$ $\left(\mathrm{Ph}_{2} \mathrm{Si}-\mathrm{NBn}\right)_{2}(\mathbf{5})$ and unreacted $\mathrm{Ph}_{2} \mathrm{SiH}_{2}$. The catalytic (5.0 mol-\% of $\left.\mathbf{A}\right)$ formation of $\mathbf{5}$ upon cyclisation of 4 with concomitant release of benzene (vide infra) also occurs at higher 
substrate concentrations $(2.0 \mathrm{M})$, oreven in the absence of $\mathrm{Ph}_{2} \mathrm{SiH}_{2}$ under otherwise identical experimental conditions $\left(60{ }^{\circ} \mathrm{C}, 2 \mathrm{~h},[\mathbf{4}]_{0} /[\mathbf{A}]_{0}=20: 1,[\mathbf{4}]_{0}=0.2 \mathrm{M}\right) .{ }^{[30]}$

Overall, the multistep sequential Ba-promoted process forming4 from triphenylsilane is unusual, as well as being highly effective and chemoselective. Like 1, silazanes 3-5 were all isolated as colourless solids, and crystals were grown from concentrated pentane solutions. Their identities were established on the basis of the NMR spectroscopic $\left({ }^{1} \mathrm{H},{ }^{13} \mathrm{C},{ }^{29} \mathrm{Si}\right)$, mass spectrometric and crystallographic data of the purified products. For these and the following related compounds, elemental analyses were often thwarted because ofhigh silicon contents, but they were overall consistent with the proposed formulations. ${ }^{[31,32]}$

\section{Reaction scope}

Starting from $\mathbf{3}$, the method employed to obtain $\mathbf{4}$ by coupling with $\mathrm{BnNH}_{2}$ was extended to other amines (Scheme 3). $\mathrm{Ph}_{3} \mathrm{SiN}(\mathrm{Bn}) \mathrm{SiPh}_{2} \mathrm{~N}\left(\mathrm{CH}_{2}\right)_{4}$ (6) was obtained in a42\% non-optimised yield upon dehydrocoupling of $\mathbf{3}$ and pyrrolidineunder mild conditions. The coupling of $\mathbf{3}$ with diamines or with primary amines is more pertinent. Instead of $\mathrm{BnNH}_{2}$ leading to the formation of $\mathbf{4}$, the $\mathrm{CDC}$ of $\mathbf{3}$ with $\mathrm{MesCH}_{2} \mathrm{NH}_{2}(\mathrm{Mes}=$ mesityl) yieldedPh ${ }_{3} \mathrm{SiN}(\mathrm{Bn}) \mathrm{SiPh}_{2} \mathrm{NHMes} \quad$ (7)quantitatively. The coupling of $\mathbf{3}$ with 1,4phenylenedimethanamine $\left(\equiv \mathrm{H}_{2} \mathrm{~N}^{\wedge \wedge \wedge} \mathrm{NH}_{2}\right) \quad$ affordedPh $3 \mathrm{SiN}(\mathrm{Bn}) \mathrm{SiPh}_{2} \mathrm{NHCH}_{2} \mathrm{C}_{6} \mathrm{H}_{4} \mathrm{CH}_{2} \mathrm{NH}_{2}$ (8). Cyclisationand formation of a $\left[\mathrm{Si}_{2} \mathrm{~N}_{2}\right]$ cyclic moiety giving a putative [ $\left.\mathrm{Si}_{2} \mathrm{~N}_{2}\right]-\mathrm{CH}_{2} \mathrm{C}_{6} \mathrm{H}_{4} \mathrm{CH}_{2} \mathrm{NH}_{2}$ species could perhaps occur in 8. To prevent suchscenario,1,1'(1,4-phenylene)bis $(N$-methylmethanamine $)\left(\equiv \mathrm{MeHN}^{\wedge \wedge \wedge} \mathrm{NHMe}\right)$ incorporating two secondary amines with $N, N^{\prime}$-dimethyl substituents was also tested in the coupling with $\mathbf{3}$, but no conversion to $\mathrm{Ph}_{3} \mathrm{SiN}(\mathrm{Bn}) \mathrm{SiPh}_{2} \mathrm{~N}(\mathrm{Me}) \mathrm{CH}_{2} \mathrm{C}_{6} \mathrm{H}_{4} \mathrm{CH}_{2} \mathrm{NHMe}$ was detected. Similar observations were made before in the couplings with $\mathrm{Ph}_{3} \mathrm{SiH}$ upon going from $\mathrm{BnNH}_{2}$, which 
is highly reactive, to the secondary amine $\mathrm{Bn}_{2} \mathrm{NH}$ which showed almost no reactivity. ${ }^{[15 \mathrm{~b}]} \mathrm{CDC}$ reactionsarehence greatly sensitive to steric effects.

Scheme 3.Synthesis of linear disilazanes catalysed by $\mathrm{Ba}\left[\mathrm{CH}\left(\mathrm{SiMe}_{3}\right)_{2}\right]_{2} \bullet(\mathrm{THF})_{3}(\mathbf{A})$ starting from $\mathrm{Ph}_{3} \mathrm{SiN}(\mathrm{Bn}) \mathrm{SiHPh}_{2}$ (3). Experimental conditions: Precatalyst A $(5.0 \mu \mathrm{mol}), \quad[\mathbf{3}]_{0} /[\mathrm{amine}]_{0} /[\mathbf{A}]_{0}=20: 20: 1$, $[\text { amine }]_{0}=0.2 \mathrm{M}$ in benzene, $60{ }^{\circ} \mathrm{C}, 2 \mathrm{~h} .{ }^{[29]}$

Starting materials other than $\mathbf{1}$ and $\mathbf{3}$ are also amenable tocouplings catalysed by $\mathbf{A}$ (Scheme 4). It has been shown that the coupling of 2 equiv of $\mathrm{Ph}_{3} \mathrm{SiH}$ with 1,4phenylenedimethanamineselectively affords $\quad \mathrm{Ph}_{3} \mathrm{SiNHCH}_{2} \mathrm{C}_{6} \mathrm{H}_{4} \mathrm{CH}_{2} \mathrm{NHSiPh}_{3} \quad$ (9). ${ }^{[15 b]}$ Thisprecursor was further subjected to coupling with 2 equiv of $\mathrm{Ph}_{2} \mathrm{SiH}_{2}$. The reaction was quantitative $\left(25^{\circ} \mathrm{C}, 2 \mathrm{~h},\left[\mathrm{Ph}_{2} \mathrm{SiH}_{2}\right]_{0} /[\mathbf{9}]_{0} /[\mathbf{A}]_{0}=200: 100: 1\right)$ and produced the bis(disilazane) $\mathrm{Ph}_{2} \mathrm{HSi}\left(\mathrm{Ph}_{3} \mathrm{Si}\right) \mathrm{NCH}_{2} \mathrm{C}_{6} \mathrm{H}_{4} \mathrm{CH}_{2} \mathrm{~N}\left(\mathrm{Ph}_{3} \mathrm{Si}\right) \mathrm{SiHPh}_{2}$ (10), which contains two hydrosilanyl functional groups in $\alpha$ and $\omega$ positions. The subsequent coupling of the difunctional 10 with lequiv of $\mathrm{H}_{2} \mathrm{~N}^{\wedge \wedge \wedge} \mathrm{NH}_{2}$ at $25{ }^{\circ} \mathrm{C}$ for $1 \mathrm{~h}\left([\mathbf{1 0}]_{0} /\left[\mathrm{H}_{2} \mathrm{~N}^{\wedge \wedge \wedge} \mathrm{NH}_{2}\right]_{0} /[\mathbf{A}]_{0}=20: 20: 1\right)$ yielded aninsoluble white solid, probablya cross-linked polycarbosilazane resulting from dehydropolymerisation;the ${ }^{1} \mathrm{H}$ and ${ }^{29} \mathrm{Si}$ NMR data ofthis material could not interpreted. The reaction of $\mathbf{1 0}$ with5 or10 equiv of $\mathrm{H}_{2} \mathrm{~N}^{\wedge \wedge \wedge} \mathrm{NH}_{2}$ Vs. A $\left([\mathbf{1 0}]_{0} /\left[\mathrm{H}_{2} \mathrm{~N}^{\wedge \wedge \wedge} \mathrm{NH}_{2}\right]_{0} /[\mathbf{A}]_{0}=20: \mathrm{X}: 1\right)$ gave intractable mixtures. $\mathrm{HSiPh}_{2} \mathrm{~N}(\mathrm{Me}) \mathrm{CH}_{2} \mathrm{C}_{6} \mathrm{H}_{4} \mathrm{CH}_{2} \mathrm{NHMe}$ (11) is a starting material for the grafting of both a dihydrosilaneor an amine, on the $-\mathrm{NHMe}$ or the $-\mathrm{NMeSiPh}_{2} \mathrm{H}$ tail-ends, respectively, or as a bifunctional $\mathrm{AB}$ monomer for dehydropolymerisation reactions to obtain 
high molecular polycarbosilazanes. ${ }^{[16]}$ Itcan be obtainedfrom the quantitative and chemoselective coupling of MeHN^^^NHMe with a single equiv of $\mathrm{Ph}_{2} \mathrm{SiH}_{2}$ (Scheme 4).

Scheme 4.Sequential grafting of various amines and hydrosilanes in CDC reactions catalysed byBa $\left[\mathrm{CH}\left(\mathrm{SiMe}_{3}\right)_{2}\right]_{2} \bullet(\mathrm{THF})_{3}(\mathbf{A}){ }^{[29]}$ All reactions performed in benzene. 
Substituents can be introduced in the amines, as in 7 (see Scheme 3), or alternatively in the hydrosilanes. For instance, $\left(p-\mathrm{CF}_{3}-\mathrm{C}_{6} \mathrm{H}_{4}\right) \mathrm{Ph}_{2} \mathrm{SiNHBn}(\mathbf{1 2})$ was prepared upon coupling of $\left(p-\mathrm{CF}_{3}-\mathrm{C}_{6} \mathrm{H}_{4}\right) \mathrm{Ph}_{2} \mathrm{SiHand} \quad \mathrm{BnNH}_{2} \quad$ (Scheme 4).The coupling of $\mathbf{1 2}$ with $\mathrm{Ph}_{2} \mathrm{SiH}_{2}\left(\left[\mathrm{Ph}_{2} \mathrm{SiH}_{2}\right]_{0} /[\mathbf{1 2}]_{0} /[\mathbf{A}]_{0}=20: 20: 1\right)$ smoothly gave $\left(p-\mathrm{CF}_{3}-\mathrm{C}_{6} \mathrm{H}_{4}\right) \mathrm{Ph}_{2} \mathrm{SiN}(\mathrm{Bn}) \mathrm{SiHPh}_{2}$ (13), which could be further reacted with $\mathrm{BnNH}_{2}$ to afford $\left(p-\mathrm{CF}_{3^{-}}\right.$ $\left.\mathrm{C}_{6} \mathrm{H}_{4}\right) \mathrm{Ph}_{2} \mathrm{SiN}(\mathrm{Bn}) \mathrm{SiPh}_{2} \mathrm{NHBn}(\mathbf{1 4})$.In the way seen for the cyclisation from $\mathbf{4}$ to $\mathbf{5}$, upon exposure to precatalyst $\mathrm{A}$ at $60{ }^{\circ} \mathrm{C}$ for $12 \mathrm{~h}$, the linear $\mathbf{1 4}$ led to the formation of $\mathbf{5}$ viaselective elimination of 1 equiv of $\mathrm{C}_{6} \mathrm{H}_{5} \mathrm{CF}_{3}$, as established by ${ }^{1} \mathrm{H}$ and ${ }^{19} \mathrm{~F}$ NMR spectroscopy. The mechanism proposed for the cyclisation, with formation of a transient pentavalent silicate and transfer of a partially negatively charged aromatic moiety to barium stabilised by para electron-withdrawing groups, accounts for the selectivity towards the elimination of $p-\mathrm{CF}_{3^{-}}$ $\mathrm{C}_{6} \mathrm{H}_{5}$ inthe production of $\mathbf{1 4}$ (vide infra). This series of reactions also work for $p$-methylsubstituted arylhydrosilanes. However, they are more sluggish reagents, e.g. requiring heating for $12 \mathrm{~h}$ at $60{ }^{\circ} \mathrm{C}$ to afford $\left(p-\mathrm{CH}_{3}-\mathrm{C}_{6} \mathrm{H}_{4}\right) \mathrm{Ph}_{2} \mathrm{SiN}(\mathrm{Bn}) \mathrm{SiPh}_{2} \mathrm{NHBn}$; further cyclisation of this compound does not even reach $10 \%$ conversion (upon selective elimination of benzene, while the release of toluene is not detected) after heating for $12 \mathrm{~h}$ at $60{ }^{\circ} \mathrm{C}$. In a rough empirical evaluation, the reactions rate therefore seems to increase when electronic density on the silicon atom decreases $\left(\mathrm{Me}<\mathrm{H}<\mathrm{CF}_{3}\right)$, and the proposed mechanism detailed in the following sections is consistent with this observation.

The formation of the cyclic product 5 upon elimination of an aromatic molecule, benzene in the case of $\mathbf{4}$ and trifluoromethylbenzene for $\mathbf{1 4}$, is not the sole method for the preparation of cyclosilazanes. The couplingof $\mathrm{BnNHCH}_{2} \mathrm{CH}_{2} \mathrm{NHBn}$ with $\mathrm{Ph}_{2} \mathrm{SiH}_{2}$ catalysed by $\mathbf{A}$ or even $\mathrm{Ba}\left[\mathrm{N}\left(\mathrm{SiMe}_{3}\right)_{2}\right]_{2} \bullet(\mathrm{THF})_{2}$ takes place readily to give the corresponding 5 -member cycle 15, $c$ - $\left[\mathrm{Ph}_{2} \mathrm{SiN}(\mathrm{Bn}) \mathrm{CH}_{2} \mathrm{CH}_{2} \mathrm{~N}(\mathrm{Bn})\right](\mathrm{Scheme} 5)$. Besides, compound 5 itself had previously 
been obtained by barium-mediated $\mathrm{H}_{2}$-releasing dehydrocoupling of $\mathrm{Ph}_{2} \mathrm{SiH}_{2}$ with $\mathrm{BnNHSiPh}_{2} \mathrm{NHBn}^{[15 \mathrm{a}]}$

Scheme 5. Formation of cyclo(di)silazanesby barium-mediated CDCreactions. ${ }^{\text {[29] }}$

The peculiarity of the formation of $\mathbf{5}$ from $\mathbf{4}$ or $\mathbf{1 4 l i e s}$ in the fact that it forms not by crossdehydrocoupling between an amine and hydrosilane with evolution of dihydrogen, but upon ring-forming, barium-catalysed $\mathrm{Si}-\mathrm{C}$ bond cleavage with concomitant elimination of one stoichiometric equivalent of aromatic by-product. Although not common, the rupture of $\mathrm{Si}-\mathrm{C}$ bonds has already been documented under other circumstances. The cleavage of $\mathrm{Si}-\mathrm{C}$ bonds under acidic conditions has long been known. ${ }^{[33]}$ More recently, several cases of metalpromoted $\mathrm{Si}-\mathrm{C}$ bond ruptures have been disclosed for both $\mathrm{C}_{s p 2}$ and $\mathrm{C}_{s p 3}$ carbon atoms. For instance, the lutetium hydride $\left[\left(\mathrm{C}_{5} \mathrm{Me}_{5}\right)_{2} \mathrm{Lu}(\mu-\mathrm{H})\right]_{2}$ was reported to cleave the $\mathrm{Si}-\mathrm{C}_{s p 2}$ bond in $\mathrm{PhSiH}_{3}$ to generate benzene and cross-linked polysilanes $\left(\mathrm{SiH}_{x}\right){ }_{y} \cdot{ }^{[34]} \mathrm{Nickel}$ and palladium silyl pincer complexes can undergo structural rearrangements implicating reversible $\mathrm{Si}-\mathrm{C}_{s p 3}$ and $\mathrm{Si}-\mathrm{C}_{s p 2}$ bond activation. ${ }^{[35]}$ The rhodium-catalysed coupling of 2-trimethylsilylphenylboronic acid with internal alkynes produces 2,3-disubstituted benzosilole derivatives. ${ }^{[36]} \mathrm{Rh}(\mathrm{H})(\mathrm{CO})\left(\mathrm{PPh}_{3}\right)_{3}$ triggers $\mathrm{Si}-\mathrm{C}_{\mathrm{R}}$ bond cleavage in $\left\{o-\left(\mathrm{Ph}_{2} \mathrm{P}\right) \mathrm{C}_{6} \mathrm{H}_{4}\right\}_{2} \mathrm{SiMeR}(\mathrm{R}$ $=\mathrm{Ph}, \mathrm{Me}, \mathrm{Et})$; it was shown that the facility of bond activation increased with temperature and 
according to $\mathrm{Si}-\mathrm{Et}<\mathrm{Si}-\mathrm{Me}<\mathrm{Si}-\mathrm{Ph} .{ }^{[37]}$ Perhaps more relevantly to the present work, the stoichiometric conversion of $\mathrm{Si}-\mathrm{C}(\operatorname{aryl}) \sigma$-bonds into $\mathrm{Si}$-heteroatom ones in the reactions of $\eta^{3}$ - $\alpha$-silabenzyl molybdenum and tungsten complexes with 2 -substituted pyridines has been reported very recently. ${ }^{[38]}$ The cleavage of $\mathrm{Si}-\mathrm{C}$ bonds is also promoted by supercritical water $^{[39]}$ or by montmorillonite. ${ }^{[40]}$

That 4 could be synthesised from 3 under catalytic conditions and obtained free of contamination by $\mathbf{5}$, whereas pure $\mathbf{4}$, once isolated and then re-dissolved in benzene in the presence of $\mathbf{A}\left(0.05\right.$ equiv, $60{ }^{\circ} \mathrm{C}, 2 \mathrm{~h}$; see Scheme 2$)$ cleanly and quantitatively yielded $\mathbf{5}$ in a catalysed process, constitutes anintriguing reactivity pattern. We are unable at this time to propose a conclusive explanation for this phenomenon. One conceivable hypothesis is that during the formation of $\mathbf{4}$ bycoupling of $\mathrm{BnNH}_{2}$ and $\mathbf{3}$, the catalyst resting state is under the form of a putative " $\left[\mathrm{Ba}(\mathrm{NHBn})_{2}(\mathrm{~S})_{x}\right]_{n}$ " species, where $\mathrm{S}$ is $\mathrm{THF}$ or $\mathrm{BnNH}_{2}{ }^{[41]}$ This species may be insufficiently basic to deprotonate the newly-formed 4 present in the reaction mixture. On the other hand, reaction of the pre-isolated, purified 4 with the highly basic barium bis(alkyl) A must produce a species akin to "Ba[N(Bn) $\left.\mathrm{SiPh}_{2} \mathrm{~N}(\mathrm{Bn}) \mathrm{SiPh}_{3}\right]_{2} \bullet(\mathrm{THF})_{n}$ "(DFT computations favours $n=0$, vide infra) by aminolysis and irreversible release of $\mathrm{CH}_{2}\left(\mathrm{SiMe}_{3}\right)_{2}$. The fact that the relatively less basic $\mathrm{Ba}\left[\mathrm{N}\left(\mathrm{SiMe}_{3}\right)_{2}\right]_{2} \bullet(\mathrm{THF})_{2}$ fails entirely to react with 4 (unreacted materials only are returned) is congruent with this working hypothesis. In the absence of any reactive substrate other than $\mathbf{4}$, if this new compound "Ba[N(Bn) $\left.\mathrm{SiPh}_{2} \mathrm{~N}(\mathrm{Bn}) \mathrm{SiPh}_{3}\right]_{2} \bullet(\mathrm{THF})_{n}$ "evolves, it can only be towards the formation of the cyclodisilazane 5. If so, this mayfor instance occur via nucleophilic attack of the $N_{\text {amide }}$ atom onto the terminal $\mathrm{Si}$ atom creating a hypervalent silicate followed by $\beta-\mathrm{C}_{6} \mathrm{H}_{5}$ transfer to $\mathrm{Ba}$, or perhaps by a less likely $\sigma$-metathetical pathway. Such processesshould give rise to a transient [Ba]-Ph species, which is basic enough to deprotonate more incoming $\mathbf{4}$ and, in doing so, regenerate "Ba[N(Bn) $\left.\mathrm{SiPh}_{2} \mathrm{~N}(\mathrm{Bn}) \mathrm{SiPh}_{3}\right] \bullet(\mathrm{THF})_{n}$ " and release benzene (Scheme 6). 
Scheme 6.Possible stepwise mechanisminvolving a transient [Ba]-Ph species for thequantitative synthesis of $c$ $\left(\mathrm{Ph}_{2} \mathrm{SiNBn}\right)_{2}$ (5) starting from $\mathrm{Ph}_{3} \mathrm{SiN}(\mathrm{Bn}) \mathrm{SiPh}_{2} \mathrm{NHBn}(\mathbf{4})$ and catalysed by $\mathrm{Ba}\left[\mathrm{CH}\left(\mathrm{SiMe}_{3}\right)_{2}\right]_{2} \bullet(\mathrm{THF})_{3}(\mathbf{A})$.

\section{Regarding the mechanism of the cyclisation reaction}

The NMR-scale reaction of $\mathbf{A}$ with 2 equiv of 4 in benzene- $d_{6}\left(2 \mathrm{~h}, 25^{\circ} \mathrm{C}\right)$ was examined by ${ }^{1}$ H NMR spectroscopy (Figure 1). It generated preponderantly a new barium compound, the ${ }^{1} \mathrm{H}$ NMR data of which- in particular two sharp singlets integrating for twohydrogens each at $\delta_{1 \mathrm{H}} 4.59$ and $4.13 \mathrm{ppm}$ and corresponding to two types of $\mathrm{C}_{6} \mathrm{H}_{5} \mathrm{CH}_{2}$ methylene hydrogens-agreed with the formulation $\mathrm{Ba}\left[\mathrm{N}(\mathrm{Bn}) \mathrm{SiPh}_{2} \mathrm{~N}(\mathrm{Bn}) \mathrm{SiPh}_{3}\right]_{2}$ (Fig. 5). Quantitative release of $\mathrm{CH}_{2}\left(\mathrm{SiMe}_{3}\right)_{2}$ was also detected, together with the presence of $\mathbf{5}$ (ca.40\%, diagnostic singlet at $\delta_{1 \mathrm{H}} 4.08 \mathrm{ppm}$ ) and minute amounts of unreacted 4 . The preparation of an authentic sample of this complex by reacting A with 2.0 equiv of $\mathbf{4}$ showed thatthe THF molecules did not remain metal-bound. The ${ }^{1} \mathrm{H}$ NMR data of the product obtained after work-up was consistent with that given in Fig. 1, but for the fact that no resonance for THF wasdetectable. Thesedata confirm that $\mathrm{Ba}\left[\mathrm{N}(\mathrm{Bn}) \mathrm{SiPh}_{2} \mathrm{~N}(\mathrm{Bn}) \mathrm{SiPh}_{3}\right]_{2}$ can be made, but also that it is unstable at room temperature. It spontaneously evolves in solution to generate 5 in increasing amounts 
over the course of $6 \mathrm{~h}$, and also partly decomposes to release 4together with unidentified barium species.

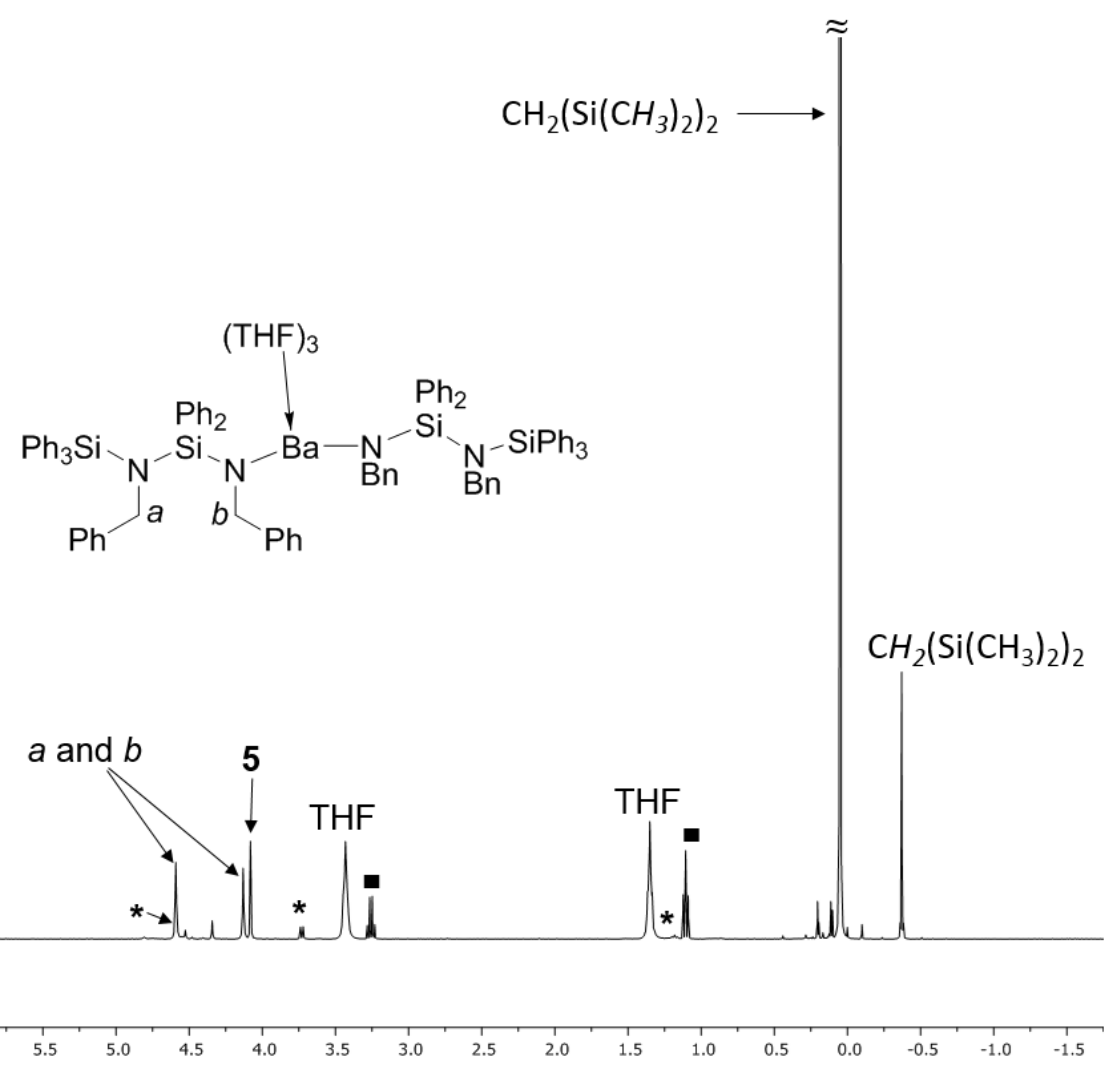

Figure 1. ${ }^{1} \mathrm{H}$ NMR spectrum (benzene- $d_{6}, \quad 25{ }^{\circ} \mathrm{C}, \quad 400.1 \mathrm{MHz}$ ) of the NMR-scale reaction of $\mathrm{Ba}\left[\mathrm{CH}\left(\mathrm{SiMe}_{3}\right)_{2}\right]_{2} \bullet(\mathrm{THF})_{3}(\mathbf{A})$ with 2 equivof $\mathrm{Ph}_{3} \mathrm{SiN}(\mathrm{Bn}) \mathrm{SiPh}_{2} \mathrm{NHBn}$ (4), showing the quantitative release of $\mathrm{CH}_{2}\left(\mathrm{SiMe}_{3}\right)_{2}$ and formation of a minor amount of $c-\left(\mathrm{Ph}_{2} \mathrm{SiNBn}\right)_{2}(\mathbf{5}) . *$ unreacted $4 . \mathbf{m}=$ residual $\mathrm{Et}_{2} \mathrm{O}$.

The formation of $\mathbf{5}$ upon addition of 20 equiv of $\mathbf{4}$ to $\mathbf{A}$ in toluene- $d_{8}$ at $60{ }^{\circ} \mathrm{C}$, i.e. under catalytic conditions, was monitored spectroscopically over the course of several hours. Gradual but eventual quantitative formation of 5together with the release of benzenecould be visualised (sharp singlet resonances at $\delta_{1 \mathrm{H}} 7.13 \mathrm{ppm}$ and $\delta_{13 \mathrm{C}} 128.53 \mathrm{ppm}$ ) concomitantly with the consumption of 4 . The kinetic rate law exhibits partial orders of 1 in both catalyst and substrate concentrations. The value of the observed rate constant, $k_{\mathrm{obs}, \mathrm{H}}=1.98 \pm 0.1 \times 10^{-5} \mathrm{~s}^{-1}$, was determined from the semi-logarithmic plot of conversion $v s$ reaction time. No primary kinetic isotopic effect was seen(the cyclisation of $\mathrm{Ph}_{3} \mathrm{SiN}(\mathrm{Bn}) \mathrm{SiPh}_{2} \mathrm{NDB}$ nalso proceeded with $\left.k_{\mathrm{obs}, \mathrm{D}}=2.00 \pm 0.1 \times 10^{-5} \mathrm{~s}^{-1}, k_{\mathrm{obs}, \mathrm{H}} / k_{\mathrm{obs}, \mathrm{D}}=0.99 \pm 0.1\right)$, indicating that the rupture of the $\mathrm{N}-\mathrm{H}$ 
bond is not a key component of the turnover-limiting step. The activation parameters $\Delta H^{\star}=$ $20.6 \pm 0.2 \mathrm{kcal} \mathrm{mol}^{-1}$ and $\Delta S^{\ddagger}=-9.5 \pm 0.1 \mathrm{cal} \mathrm{mol}^{-1} \mathrm{~K}^{-1}\left(\Delta G^{\ddagger}=23.4 \pm 0.1 \mathrm{kcal} \mathrm{mol}^{-1}\right.$ at $\left.298 \mathrm{~K}\right)$ were extracted by Eyring analysis of kinetic data recorded in the temperature range 328-353 $\mathrm{K}$ (5 data points).The cyclisation $\mathbf{4} \rightarrow \mathbf{5}$ uponexclusive elimination of $\mathrm{C}_{6} \mathrm{H}_{5} \mathrm{CF}_{3}$ from $\mathbf{1 4}$ proceeds with $k_{\mathrm{obs}}=5.16 \pm 0.1 \times 10^{-5} \mathrm{~s}^{-1}$. Enhancement of the cyclisation rate on adding an electron-withdrawing group in the para position of one of the aryl rings on the silicon atom that undergoes ring-closure is consistent with the existence of a negative charge developing on this $\mathrm{Si}$ atom in the transition state. Finally, that the formation of $\left(\mathrm{C}_{6} \mathrm{D}_{5}\right)_{3} \mathrm{SiN}(\mathrm{Bn}) \mathrm{SiPh}_{2} \mathrm{~N}(\mathrm{Bn}) \mathrm{H}$ (or its $\left(\mathrm{C}_{6} \mathrm{D}_{5}\right)_{\mathrm{x}}(\mathrm{Ph})_{3-\mathrm{x}} \mathrm{SiN}(\mathrm{Bn}) \mathrm{Si}\left(\mathrm{C}_{6} \mathrm{D}_{5}\right)_{\mathrm{x}},(\mathrm{Ph})_{2-\mathrm{x}} \mathrm{N}(\mathrm{Bn}) \mathrm{H}$ parents) is not detected when the benzene-releasing transformation $\mathbf{4} \rightarrow \mathbf{5}$ is carried out in benzene$d_{6}$ over several hours reveals that this ring-closing process is irreversible. Considered collectively, these observations are compatible with a mechanism such as that described in Scheme 6.

Importantly, no ring-closure takes place when $\mathrm{Me}_{3} \mathrm{SiN}(\mathrm{Bn}) \mathrm{SiPh}_{2} \mathrm{NHBn}$ (18), with alkyl instead of aryl substituents on the tail-end silicon atom, is heated in benzene- $d_{6}$ for $12 \mathrm{~h}$ at $60{ }^{\circ} \mathrm{C}$ in the presence of $5.0 \mathrm{~mol}-\%$ of $\mathbf{A}$. The compound remains unreacted throughout the course of the experiment, with no evolution detected spectroscopically. The release of benzene in the cyclisation process from $\mathbf{4}$ to $\mathbf{5}$ (instead of an alkane from 18) seems to bea key driving force, or at least one can safely conclude that for this process, $\mathrm{Si}-\mathrm{C}_{s p 2}$ bonds are more likely to undergo activation than $\mathrm{Si}-\mathrm{C}_{s p 3}$ ones. Compound $\mathbf{1 8}$ had first been isolated after the two-step sequential procedure (Scheme 7) involving the coupling of the known $\mathrm{Me}_{3} \mathrm{SiNHBn}$ (16) with $\mathrm{Ph}_{2} \mathrm{SiH}_{2}$ to afford $\mathrm{Me}_{3} \mathrm{SiN}(\mathrm{Bn}) \mathrm{SiHPh}_{2}$ (17), followed by the coupling of 17 with $\mathrm{BnNH}_{2}{ }^{[42]}$ 
Scheme 7.Catalytic synthesis of $\mathrm{Me}_{3} \mathrm{SiN}(\mathrm{Bn}) \mathrm{SiPh}_{2} \mathrm{NHBn}(\mathbf{1 8})$.

The benzene-releasing cyclisation from $\mathbf{4}$ to $\mathbf{5}$ is not specific to barium precatalysts. It is also for instance catalysed by $\mathrm{Ca}\left[\mathrm{CH}\left(\mathrm{SiMe}_{3}\right)_{2}\right]_{2} \bullet(\mathrm{THF})_{2}(\mathbf{B})$, the calcium analogue of $\mathbf{A}$. In a control experiment performed under otherwise identical experimental conditions $\left([4]_{0} /[\text { precatalyst }]_{0}=20: 1,60{ }^{\circ} \mathrm{C}\right.$ in benzene, $\left.[\text { precatalyst }]_{0}=10 \mathrm{mM}\right), \mathbf{B}$ catalyses the reaction at a rate very comparable to that of $\mathbf{A}, k_{\mathrm{obs}}=9.16 \pm 0.3 \times 10^{-6} \mathrm{~s}^{-1}$ and $1.98 \pm 0.1 \times 10^{-5} \mathrm{~s}^{-1}$, respectively. Eyring analyses in the temperature range 328-353 K (5 data points) allowed to calculate the activation parameters for $\mathbf{B}, \Delta H^{\ddagger}=16.8 \pm 0.1 \mathrm{kcal} \mathrm{mol}^{-1}$ and $\Delta S^{\ddagger}=-22.3 \pm 0.1 \mathrm{cal}$ $\mathrm{mol}^{-1} \mathrm{~K}^{-1}$, with $\Delta G^{\ddagger}=23.4 \pm 0.1 \mathrm{kcal} \mathrm{mol}^{-1}$ at $298 \mathrm{~K}$. This lastvalue replicatesthat for $\mathbf{A}$, but the respective enthalpic and entropic contributions are very different. Due to itsmuch smaller size compared to barium (effective $r_{\text {ionic }}$ for C.N. $=6: \mathrm{Ca}^{2+}, 1.00 \AA$; $\mathrm{Ba}^{2+}, 1.38 \AA$ ), the greater entropic factor for calcium becomes unfavourable as the temperature of the reaction is increased. The energy of activation determined by Arrhenius analysis is actually lower for the calcium precatalyst $\mathbf{B}\left(E_{\mathrm{a}}=17.5 \pm 0.1 \mathrm{kcal} \mathrm{mol}^{-1} ; R^{2}=0.9923\right)$ than for the barium $\mathbf{A}\left(E_{\mathrm{a}}=\right.$ $\left.21.3 \pm 0.2 \mathrm{kcal} \mathrm{mol}^{-1} ; R^{2}=0.9946\right)$.

\section{Computational investigations}

A reliable state-of-the-art density functional theory (DFT) method has been employed to complement the mechanistic studies reported above with an aim to further enhance our understanding of mechanistic intricacies behind the generation of cyclodisilazanes. We have examined various mechanistic pathways conceivable for the conversion of disilazane 4 into the 4-membered cyclodisilazane 5 by the barium precatalystA (denoted $\mathbf{C 1} \cdot(\mathrm{T})^{3}$ hereafter). For 
the disilazane, the two silicon-bound phenyl spectator groups have been replaced by methyl ones $\left(\mathbf{4}_{\mathrm{Me}}\right)$ for the sole purpose of expediting computations, but no further simplifications of any kind has been imposed for any of the key species involved. The computational methodology employed (dispersion-corrected B97-D3 in conjunction with triple- $\zeta$ basis sets and a sound treatment of bulk solvent effects; see the Computational methodology in the SI) adequately simulated the authentic reaction conditions and has been demonstrated before to reliably map the free-energy landscape of alkaline earth-mediated hydroelementation reactions. ${ }^{[15,43]}$ This has allowed mechanistic conclusions with substantial predictive value to be drawn.

We started with an examination of the Ba-C alkyl bond aminolysis at starting material $\mathbf{C 1} \cdot(\mathrm{T})^{3} \quad(\equiv \mathbf{A}) \quad$ by $\quad \mathbf{4}_{\mathrm{Me}}$, thereby transforming $\mathbf{C 1} \cdot(\mathrm{T})^{3}$ into the related $\left[\mathrm{Ba}\left\{\mathrm{N}(\mathrm{Bn}) \mathrm{SiMe}_{2} \mathrm{~N}(\mathrm{Bn}) \mathrm{SiMe}_{2} \mathrm{Ph}\right\}_{2}\right]$ barium bis-amido compound $\mathbf{C 2}$, which is likely competent triggering the $\mathbf{4}_{\mathrm{Me}} \rightarrow \mathbf{5}_{\mathrm{Me}}$ conversion. The activation of $\mathrm{C} \mathbf{1} \bullet(\mathrm{T})^{3}$ entails that amine binds initially at barium. Several pathways, which are distinguished by the number of THF molecules to remain bound at barium, have been examined, the most accessible one (Figure S18) togetherwith the complete account of all the studied pathways (Figures S17-S20) can be found in the Supporting Information. The energetically prevalent pathway for $\mathrm{Ba}-\mathrm{C}$ alkyl bond aminolysis sees the first exchange of one THF for an amine molecule and to evolve through a metathesis-type transition-state (TS) structure to deliver intermediate $\mathbf{C I} 2 \cdot(\mathrm{T})^{2} \cdot \mathrm{RSi}$ featuring a barium-bound $\mathrm{H}_{2} \mathrm{C}\left(\mathrm{SiMe}_{3}\right)_{2}$ moiety. Its rapid displacement by another amine molecule prepares for protonolytic cleavage of the second $\mathrm{Ba}-\mathrm{C}$ alkyl bond via a similar metathesis-type TS structure that decays thereafter into $\mathbf{C 2}$ with the rapid release of $\mathrm{H}_{2} \mathrm{C}\left(\mathrm{SiMe}_{3}\right)_{2}$ and THF. The $\mathrm{Ba}-\mathrm{C}$ alkyl bond protonolysis has an affordable barrier of 16.7 $\mathrm{kcal} \mathrm{mol}^{-1}$ (for aminolysis of the first $\mathrm{Ba}-\mathrm{C}$ bond, Figure S18) to overcome and is driven by a huge thermodynamic force that amounts to $35.3 \mathrm{kcal} \mathrm{mol}^{-1}$. Hence, one can safely conclude 
that barium bis-alkyl $\mathbf{C 1} \cdot(\mathrm{T})^{3}$ is likely converted irreversibly in a quantitative fashion by $\mathbf{4}_{\mathrm{Me}}$ into the competent barium bis-silazanyl amido compound $\mathbf{C 2}$.

In light of the above revealed distinct reactivity pattern of $\mathbf{4}$, on the one hand, when generated under conditions of CDC catalysis (hence in the presence of benzylamine) or alternatively in the absence of any amine substrate other than $\mathbf{4}$, we deemed it instructive to study the aminolysis of $\mathbf{C 1} \cdot(\mathrm{T})^{3}$ by $\mathrm{NH}_{2} \mathrm{Bn}$ and the conversion of the thus formed barium bisbenzylamido $\mathbf{C 3}$ into $\mathbf{C 2}$ as well. The sequential protonolytic displacement of a hydrocarbyl by an amido group by both $\mathbf{4}_{\mathrm{Me}}$ or $\mathrm{NH}_{2} \mathrm{Bn}$ share structural features and theirenergy profiles are similar. For the less encumbered primary $\mathrm{NH}_{2} \mathrm{Bn}$, the most accessible pathway (see Figure S22, but also Figures S21-S24in the SI)proceeds after the initial displacement of all three THF molecules by amine with a moderate overall barrier of $7.5 \mathrm{kcal} \mathrm{mol}^{-1}$ to engage thereafter in the cleavage of the remaining $\mathrm{Ba}-\mathrm{C}$ bond, thereby affording the $\mathrm{NH}_{2} \mathrm{Bn}$ adduct C3. $(\mathrm{Am})^{3}$ of the barium bis-benzylamido compound. Overall, the conversion of starting material $\mathbf{C 1} \cdot(\mathrm{T})^{3}$ in the presence of $\mathbf{4}_{\mathrm{Me}}$ or $\mathrm{NH}_{2} \mathrm{Bn}$ into the respective barium bis-amido compounds is found affordable kinetically and strongly downhill, driven by a thermodynamic force of comparable substantial amount.

For the experimental setup of CDC catalysis to be applied, the barium bis-benzylamido, which is predominantly present as amine adduct $\mathbf{C 3} \cdot(\mathrm{Am})^{3}$, is likely representing the catalyst resting state. ${ }^{[15]}$ Hence, under such conditions $\mathbf{C 3}$ needs first to be converted into $\mathbf{C 2}$ to proceed along the various conceivable avenues that lead to the formation of the cyclodisilazane. Interestingly, the sequential exchange of benzylamido by silazanyl amido appears to be equally viable kinetically, featuring an overall activation energy of $11.3 \mathrm{kcal}$ $\mathrm{mol}^{-1}$ which is linked to aminolysis of the first $\mathrm{Ba}-\mathrm{N}$ amido bond, along the energetically prevalent pathway (see Figure S26; see also Figures S25-S28in the SI) that proceeds from the bis-silazane adduct $\mathbf{C 3} \cdot\left(\mathbf{4}_{\mathrm{Me}}\right)^{2}$. However, the thermodynamic force associated with the overall 
transformation of $\mathbf{C 3}$ into $\mathbf{C 2}$ is found strikingly different to the findings for starting material $\mathbf{C 1} \cdot(\mathrm{T})^{3}$. In sharp contrast to the huge negative reaction free energy predicted there, which is indicative of an irreversible and essentially quantitative conversion of $\mathbf{C 1} \cdot(\mathrm{T})^{3}$ into the respective barium bis-amido compounds, the process here does not benefit from a massive thermodynamic driving force, but is rather thermoneutral with $\mathbf{C 3} \cdot(\mathrm{Am})^{3} \rightleftarrows \mathbf{C 2}$ likely in a mobile equilibrium, which does not favour C2over C3. The benzylamido ligand is thus predicted to effect deprotonation of $\mathbf{4}_{\mathrm{Me}}$ substantially less effectively than the more basic hydrocarbyl ligand is capable of. The ineffectiveness of the protonolytic exchange of benzylamido by silazanyl amido at $\mathbf{C 3} \cdot(\mathrm{Am})^{3}$ due to unfavourable thermodynamics limits the population of $\mathbf{C 2}$ under conditions optimal for CDC catalysis. Given that $\mathbf{C 2}$ cannot be expected to be present in appreciable amounts under such conditions, it explains why the formation of cyclodisilazane $\mathbf{5}$ could not be observed during catalytic experiments.

The barium bis-silazanyl amido compound $\mathbf{C 2}$ is predicted to be predominantly present without amine or THF molecules directly bound to barium, featuring a metal centre that is capable of accommodating THF molecules at moderate costs, whilst the propensity of $\mathbf{4}_{\mathrm{Me}}$ to bind is substantially less pronounced.

Turning now to the plausible mechanistic proposal outlined in Scheme 6, it comprises NSi bond forming cyclisation at $\mathbf{C 2}$ with $\beta-\mathrm{C}_{6} \mathrm{H}_{5}$ abstraction from the thus formed barium silicate $\mathbf{C 4}$, all of which could proceed via stepwise or metathesis-like pathways, to furnish a barium amido phenyl compound C5to which cyclodisilazane $5_{\mathrm{Me}}$ may be bound. Protonolytic cleavage of the $\mathrm{Ba}-\mathrm{C}$ phenyl bond at $\mathbf{C 5}$ by another molecule of $\mathbf{4}_{\mathrm{Me}}$ would regenerate $\mathbf{C 2}$ with release of 1 equiv of benzene.

Commencing from $\mathbf{C 2}$, the initial $\mathrm{N}-\mathrm{Si}$ bond forming cyclisation evolves through a TS structure that describes ring closure via nucleophilic attack of the metal-bound amido nitrogen at the terminal silicon within the vicinity of the barium centre at distances of around 2.41 and 
$2.67 \AA$ (see Figure S29in the SI) for the emerging N-Si and dative Ba-N bonds, respectively. The terminal phenyl group, featuring an already elongated $\mathrm{Si}-\mathrm{C}$ linkage (1.94 $\mathrm{A}$ ) is suitably aligned towards the barium centre. Following the reaction path further, the TS structure decays into a metastable nucleophilic silicate intermediate $\mathbf{C 4}$ with a five-coordinate silicon centre carrying a partial negative charge. The cyclisation has an activation barrier of $18.7 \mathrm{kcal}$ $\mathrm{mol}^{-1}$ to overcome along the most accessible pathway (Figure 2), which does not see the participation of additional metal-bound amine molecules (see Figure S30 in the SI), to afford the metastable high-energy barium silicate $\mathbf{C 4}$. It characterises $\mathrm{C}-\mathrm{N}$ bond forming ring closure to be kinetically affordable and reversible with $\mathbf{C 2} \rightleftarrows \mathbf{C 4}$ are in a mobile equilibrium that favours strongly $\mathbf{C 2}$. A metal-bound amine molecule appears to counterbalance to some extent the weakening of the $\mathrm{Ba}-\mathrm{N}$ linkage in the TS structure and also the silicate intermediate, but additional $\mathbf{4}_{\mathrm{Me}}$ is found to not serve stabilising any of the key species involved (see Figure S30).

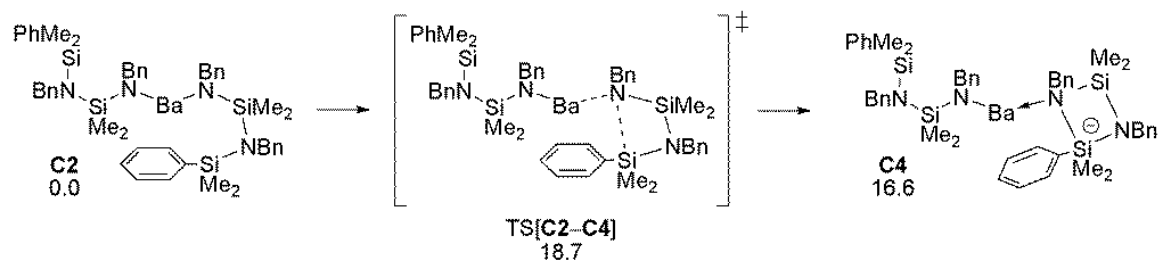

Figure 2. N-Si bond forming cyclisation at barium bis-silazanyl amido C2. Energies are given in kcal mol ${ }^{-1}$ relative to $\left\{\mathrm{C} 2+\mathrm{n} \times \mathbf{4}_{\mathrm{Me}}\right\}$.

As already indicated by its profoundly elongated $\mathrm{Si}-\mathrm{Ph}$ linkage $(2.09 \AA)$ together with a suitably towards barium oriented phenyl group, silicate $\mathbf{C 4}$ shows a distinct aptitude to undergo $\beta-\mathrm{C}_{6} \mathrm{H}_{5}$ abstraction from the five-coordinate terminal silicon onto barium. It evolves through a TS structure with distances of approximately 2.83 and $2.75 \AA$ for vanishing $\mathrm{Si}-\mathrm{C}$ and emerging $\mathrm{Ba}-\mathrm{C}$ phenyl bonds (see Figure S31in the SI), respectively, and generates the cyclodisilazane $\mathbf{5}_{\mathrm{Me}}$ bound to barium silazanyl amido phenyl C5. 


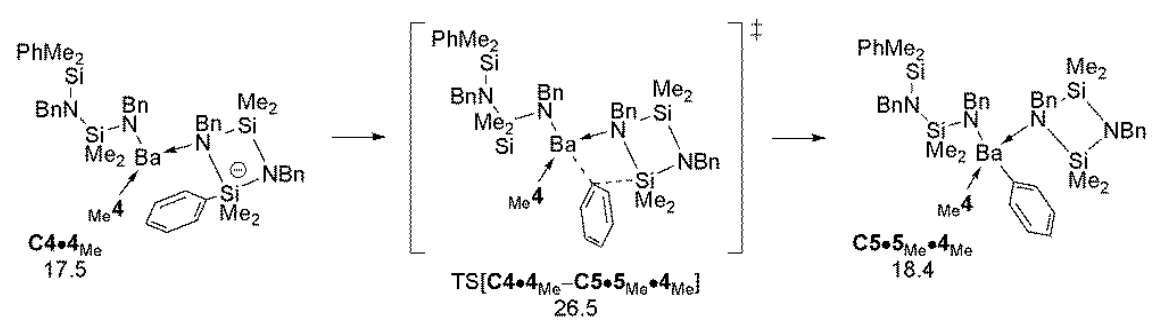

Figure 3. $\beta-\mathrm{C}_{6} \mathrm{H}_{5}$ transfer onto the metal centre at barium silicate $\mathbf{C 4}$. Energies are given in $\mathrm{kcal} \mathrm{mol}^{-1}$ relative to $\left\{\mathbf{C} 2+\mathrm{n} \times \mathbf{4}_{\mathrm{Me}}\right\}$.

Focusing at first on the intrinsic reactivity, an additionally associated $\mathbf{4}_{\mathrm{Me}}$ molecule is seen facilitating the process on both kinetic and thermodynamic grounds (see Figures 3 and S32). Phenyl transfer along the favourable $\mathbf{C 4} \cdot \mathbf{4}_{\mathrm{Me}} \rightarrow \mathbf{C 5} \cdot \mathbf{5}_{\mathrm{Me}} \cdot \mathbf{4}_{\mathrm{Me}}$ pathway (Figure 3) features a rather modest intrinsic activation barrier $\left(\Delta G^{\ddagger}{ }_{\text {int }}=9.0 \mathrm{kcal} \mathrm{mol}^{-1}\right.$, relative to $\left.\mathbf{C 4} \cdot \mathbf{4}_{\mathrm{Me}}\right)$ and is virtually thermoneutral $\left(\Delta G_{\mathrm{int}}=0.9 \mathrm{kcal} \mathrm{mol}^{-1}\right.$, relative to $\left.\mathbf{C 4} \cdot \mathbf{4}_{\mathrm{Me}}\right)$. Hence, as far as intrinsic reactivity is concerned, phenyl transfer is found to proceed more rapidly than preceding cyclisation, with $\mathbf{C 4 \cdot \mathbf { 4 } _ { \mathrm { Me } }}$ and $\mathbf{C 5} \cdot \mathbf{5}_{\mathrm{Me}} \cdot \mathbf{4}_{\mathrm{Me}}$ expected to participate in a mobile equilibrium, but without a distinct thermodynamic preference for either side. However, the unfavourable thermodynamic profile of the $\mathbf{C 2} \rightleftarrows \mathbf{C} 4$ ring closure (together with $\mathbf{4}_{\mathrm{Me}}$ complexation at $\mathbf{C 4}$ ) markedly favours $\mathbf{C 2}$ over $\mathbf{C 4} \cdot \mathbf{4}_{\mathrm{Me}}$, which renders the second phenyl transfer of the stepwise $\mathrm{C} 2 \rightleftarrows \mathrm{C4}\left(+\mathbf{4}_{\mathrm{Me}}\right) \rightleftarrows \mathrm{C4} \cdot \mathbf{4}_{\mathrm{Me}} \rightleftarrows \mathrm{C5} \cdot \mathbf{5}_{\mathrm{Me}} \cdot \mathbf{4}_{\mathrm{Me}}$ more kinetically demanding.

As already mentioned above, $\mathrm{Ba}-\mathrm{N} / \mathrm{Si}-\mathrm{C} \sigma$-bond breaking metathesis commencing from C2 describes the concerted analogue to the thus far studied stepwise generation of $\mathbf{C 5}$ (see the SI for more details).

The protonolytic cleavage of the $\mathrm{Ba}-\mathrm{C}$ phenyl bond at $\mathrm{C5}$ by another molecule of $\mathbf{4}_{\mathrm{Me}}$ regenerates barium bis-silazanyl amido $\mathbf{C 2}$, which is accompanied by the release of benzene. The process commencing from the mono-amine adduct $\mathbf{C 5} \cdot \mathbf{5}_{\mathrm{Me}} \cdot \mathbf{4}_{\mathrm{Me}}$ evolves through a metathesis-type TS structure (see Figure S33in the Supporting Information) that decays through facile liberation of benzene initially into a $\mathbf{5}_{\mathrm{Me}}$ adduct of $\mathbf{C 2}$ from which $\mathbf{5}_{\mathrm{Me}}$ is 
released readily. ${ }^{[4]}$ The protonolytic expulsion of the phenyl ligand is seen to be astonishingly facile kinetically, featuring an intrinsic barrier of $3.7 \mathrm{kcal} \mathrm{mol}^{-1}$ (relative to $\mathbf{C 5} \cdot \mathbf{5}_{\mathrm{Me}} \cdot \mathbf{4}_{\mathrm{Me}}$ ), and is strongly exergonic (Figure 4). The subsequent rapid release of the cyclodisilazane from $\mathbf{C 2} \cdot \mathbf{5}_{\mathrm{Me}}$ drives the overall aminolysis step even further downhill. Furthermore, $\mathbf{C 5} \cdot \mathbf{5}_{\mathrm{Me}} \cdot \mathbf{4}_{\mathrm{Me}}$ is likely showing a higher propensity towards undergoing forward protonolytic $\mathrm{Ba}-\mathrm{C}$ phenyl bond cleavage than reverse $\mathrm{Si}-\mathrm{C}$ bond forming phenyl transfer. In light of the predicted kinetic gap of $4.4 \mathrm{kcal} \mathrm{mol}^{-1}\left(\Delta \Delta G^{\ddagger}\right.$ between $\mathbf{C 5} \cdot \mathbf{5}_{\mathrm{Me}} \cdot \mathbf{4}_{\mathrm{Me}} \rightarrow \mathbf{C 2} \cdot \mathbf{5}_{\mathrm{Me}}+\mathrm{PhH}$ and $\mathbf{C 5} \cdot \mathbf{5}_{\mathrm{Me}} \cdot \mathbf{4}_{\mathrm{Me}} \rightleftarrows \mathbf{C 4} \cdot \mathbf{4}_{\mathrm{Me}}$ ) in favour of the forward protonolysis, $\mathbf{C 5} \cdot \mathbf{5}_{\mathrm{Me}} \cdot \mathbf{4}_{\mathrm{Me}}$ likely is a short-lived intermediate that becomes converted into $\mathbf{C 2 \cdot \mathbf { 5 } _ { \mathrm { Me } }}$ almost immediately after it is generated. Hence, $\operatorname{TS}\left[\mathbf{C 5} \cdot \mathbf{5}_{\mathrm{Me}} \cdot \mathbf{4}_{\mathrm{Me}}-\mathbf{C 2} \cdot \mathbf{5}_{\mathrm{Me}}\right]$ of the favourable protonolysis pathway shown in Figure 4does not define the highest point to be crossed along the minimum-energy pathway for generation of the cyclodisilazane, but $\operatorname{TS}\left[\mathbf{C 4} \cdot \mathbf{4}_{\mathrm{Me}}-\mathbf{C 5} \cdot \mathbf{5}_{\mathrm{Me}} \cdot \mathbf{4}_{\mathrm{Me}}\right]$ for $\beta-\mathrm{C}_{5} \mathrm{H}_{6}$ transfer onto barium (Figure 3) does.

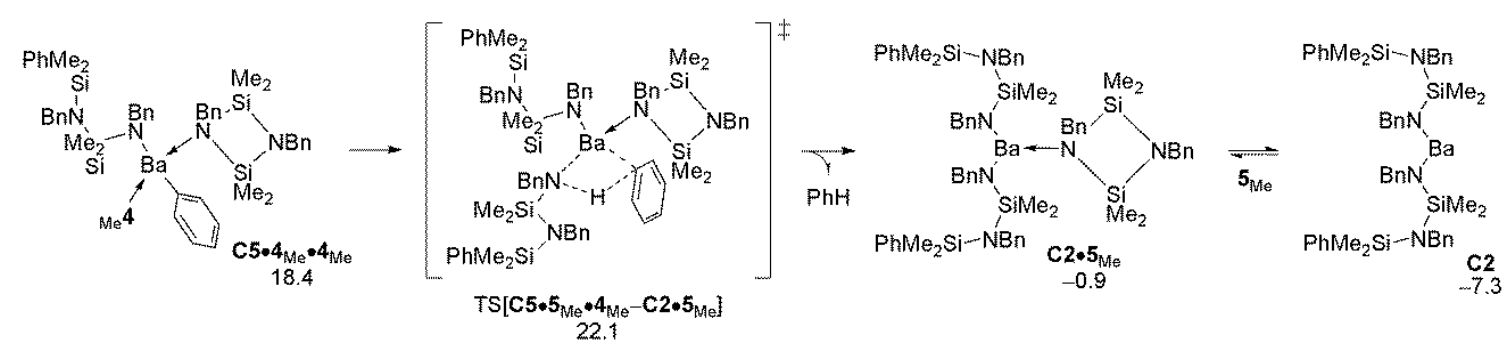

Figure 4. Ba-C phenyl bond protonolysis at barium phenyl amido C5. Energies are given in kcal mol ${ }^{-1}$ relative $^{-}$ to $\left\{\mathrm{C} 2+\mathrm{n} \times \mathbf{4}_{\mathrm{Me}}\right\}$.

Whilst exploring the existence of alternative mechanistic avenues, we managed to successfully locate a multicentre TS structure that is linked to barium silicate $\mathbf{C 4} \cdot \mathbf{4}_{\mathrm{Me}}$ describing $\beta-\mathrm{C}_{6} \mathrm{H}_{5}$ transfer with concomitant $\mathbf{4}_{\mathrm{Me}}$ amine proton delivery onto phenyl, all taking place outside of the immediate vicinity of the metal centre (see the SI for more details). 
Overall, the reported computational examination of several mechanistic avenues rationalises the distinct reactivity pattern of disilazane $\mathbf{4}$ observed under varying experimental setups and defines the most accessible among the various examined pathways for its conversion into cyclodisilazane5. It involves (1) kinetically affordable and reversible $\mathrm{N}-\mathrm{Si}$ bond forming cyclisation through nucleophilic attack of the barium silazanyl amido at the terminal silicon, (2) reversible $\beta-\mathrm{C}_{6} \mathrm{H}_{5}$ transfer onto the barium centre at the thus generated barium silicate to be followed by (3) rapid and strongly downhill $\mathrm{Ba}-\mathrm{C}$ phenyl bond aminolysis to regenerate the barium bis-silazanyl amido with concomitant release of benzene. The TS structure for $\beta-\mathrm{C}_{6} \mathrm{H}_{5}$ transfer represents the species of highest energy traversed along the identified minimum-energy pathway. The DFT-derived effective barrier of $26.2 \mathrm{kcal} \mathrm{mol}^{-1}$ for conversion of $\mathbf{4}_{\mathrm{Me}}$ into $\mathbf{5}_{\mathrm{Me}}$ mediated by barium precatalyst $\mathrm{A}$ compares favourably with experimentally determined Eyring parameters for the $\mathbf{4} \rightarrow \mathbf{5}$ transformation. The operative mechanism for the novel Ae-mediated conversion of disilazane 4 into cyclodisilazane 5 established herein through complementary kinetic analysis and DFT investigations is consistent with all relevant process features, including the rate dependency observed upon varying concentrations of precatalyst and/or substrate, ${ }^{[44]}$ the absence of a primary KIE to be detectable and the enhancement of the rate observed for disilazanes with a para-phenyl substituted terminal silicon centre featuring electron-withdrawing groups.

\section{Concluding remarks}

The bariumalkyl precatalyst $\mathrm{Ba}\left[\mathrm{CH}\left(\mathrm{SiMe}_{3}\right)_{2}\right]_{2} \cdot(\mathrm{THF})_{3}$ enables the preparation of unusual silazanes of various sizes and compositions upon iterative dehydrocouplings of primary amine and secondary dihydrosilanes. Up to now, molecules with $\mathrm{Si}-\mathrm{N}-\mathrm{Si}-\mathrm{N}$ sequences of up to four backbone heteroatoms have been obtained in quantitative yields and entire chemoselectivity under mild conditions. We are hoping to extend this methodology of sequential 
dehydrocouplings to higher degrees, i.e. for the syntheses of oligo- and polycarbosilazanes of increasing sizes and multiple compositions. For now, this ambition has been hampered by an unforeseen phenomenon of cyclisation leading to the formation of thermodynamically stable four-member $\mathrm{Si}_{2} \mathrm{~N}_{2}$ cyclodisilazanes such as $c-\left(\mathrm{Ph}_{2} \mathrm{Si}-\mathrm{NBn}\right)_{2}(5)$. The main lines of the mechanism leading to the benzene-releasing cyclisation of $\mathrm{Ph}_{3} \mathrm{SiN}(\mathrm{Bn}) \mathrm{SiPh}_{2} \mathrm{NHBn}$ (4) have been clearly delineated. The identified operativestepwise process involves the initial facile formation of a $\left[\mathrm{Ba}\left\{\mathrm{N}(\mathrm{Bn}) \mathrm{SiPh}_{2} \mathrm{~N}(\mathrm{Bn}) \mathrm{SiPh}_{3}\right\}_{2}\right]$ species, whereupon the intramolecular nucleophilic attack of the metal-bound amide onto the terminal silicon atom generates a fivecoordinate silicate is followed by turnover-limiting $\mathrm{C}_{6} \mathrm{H}_{5}$-transfer to barium. This releases the cyclic disilazane $c-\left(\mathrm{Ph}_{2} \mathrm{Si}-\mathrm{NBn}\right)_{2}$ and produces a transient $[\mathrm{Ba}]-\mathrm{Ph}$ species which is irreversibly protonolysed by another $\mathrm{Ph}_{3} \mathrm{SiN}(\mathrm{Bn}) \mathrm{SiPh}_{2} \mathrm{NHBnmolecule}$ to regenerate the competent $[\mathrm{Ba}]-\mathrm{N}(\mathrm{Bn}) \mathrm{SiPh}_{2} \mathrm{~N}(\mathrm{Bn}) \mathrm{SiPh}_{3}$ species.

Regarding the synthesis of long chain linear polycarbosilazanes, we are now considering the introduction of substituents which, by their steric or electronic effects, will privilege chain growth over cyclisation. One other possibility is to employ hydrosilanes bearing aliphatic substituentsonly, since cyclisation is exclusively driven by the release of aromatic molecules while it does not occur when the chain growth is initiated from, for instance, a triethylsilanyl fragment. However, this must be evaluated in the light of the limited reactivity displayed elsewhere by alkylsilanes in $\mathrm{N}-\mathrm{H} / \mathrm{H}-\mathrm{Si}$ dehydrocouplings. ${ }^{[15 b]}$ Optimising the conditions for the barium-mediated dehydropolymerisation ${ }^{[16]}$ of $\mathrm{HSiPh}_{2} \mathrm{~N}(\mathrm{Me}) \mathrm{CH}_{2} \mathrm{C}_{6} \mathrm{H}_{4} \mathrm{CH}_{2} \mathrm{NHMe}$ (and the likes of it), an $\alpha, \omega$-bifunctional monomer synthesised here (11) for the first time, is another option. Our efforts towards the preparation of polycarbosilazane preceramic polymers ${ }^{[10]}$ will be reported in due course.

The formation of cyclodisilazanes also conveys significant interest, since they are valuable monomers for the synthesis of linear, high molecular weight polysilazanes. ${ }^{[5,6 a]}$ It is 
by no means restricted to aromatic-substituted amines and hydrosilanes, but can be extended to many primary and secondary amines. This opens access to the preparation of a broad range of such products. Even though methods for the preparation of cyclodisilazanes have been known a number of years, ${ }^{[6 a]}$ including by cyclization of bis(methylamino)silanes with chlorosilanes ${ }^{[45]}$ or pyrolysis of diaminodiorganosilanes,${ }^{[46]}$ none is as general and versatile as the barium-catalysed cyclisation process described here. Besides, it is easily implemented (even if so far our attempts at carrying out one-pot, multi-step syntheses with a single load of precatalyst have been rewarded by limited success, possibly due to the high sensitivity of the catalytically active species), does not require harsh experimental conditions and is relatively atom-efficient.

\section{Supporting information}

General procedures, synthetic protocols and complete characterisation for all new compounds, crystallographic data for $\mathbf{1}$ and 3-5(CCDC 1435967-1435970), kinetic measurements andDFT computational methodologyare available in the Supporting Information.

\section{Acknowledgments}

C. B. thanks the University of Rennes 1 for a $\mathrm{Ph}$. D. scholarship.

\section{Notes and References}

[1] M. Lappert, P. P. Power, A. Protchenko, A. Seeber, Metal Amide Chemistry, John Wiley \& Sons, Ltd., Chichester, 2009.

[2] L. F. Fieser,M. Fieser, Reagents inOrganic Chemistry, Wiley, New York, 1967.

[3] a) Y. Tanabe, M. Murakami, K. Kitaichi,Y. Yoshida, Tetrahedron Lett.1994, 35, 8409;

b) Y. Tanabe, T. Misaki, M. Kurihara, A. Iida,Y. Nishii, Chem. Commun.2002, 1628. 
[4] a) P. J. Kocieński, Protecting Groups, 3rd ed., Thieme, Stuttgart, 2005, pp. 595-599; b) D. W. Robbins, T. A. Boebel,J. F. Hartwig, J. Am. Chem. Soc.2010, 132, 4068; c) S. Itagaki, K. Kamata, K. Yamaguchi, N. Mizuno, Chem. Commun.2012, 48, 9269; d) T. Tsuchimoto, Y. Iketani,M. Sekine, Chem. Eur. J.2012, 18, 9500; e) C. D. F. Königs, M. F. Müller, N. Aiguabella, H. F. T. Klare,M. Oestreich, Chem. Commun.2013, 49, 1506; f) L. Greb, S. Tamke,J. Paradies, Chem. Commun.2014, 50, 2318.

[5] a) D. Seyferth,G. H. Wiseman, J. Am. Ceram. Soc.1984, 67, C-132; b) D. Seyferth, J. M. Schwark, R. M. Stewart, Organometallics1989, 8, 1980; c) E. Duguet, M. Schappacher, A. Soum, Macromolecules1992, 25, 4835; d) M. Bouquey, C. Brochon, S. Bruzaud, A-F. Mingotaud, M. Schappacher, A. Soum, J. Organomet. Chem.1996, 521, 21; e) S. Bruzaud, A. Soum, Macromol. Chem. Phys.1996, 197, 2379; f) S. Bruzaud, A.-F. Mingotaud, A. Soum, Macromol. Chem. Phys.1997, 198, 1873; g) C. Cazalis, A.F. Mingotaud, A. Soum, Macromol. Chem. Phys.1997, 198, 3441; h) D. Seyferth, R. M. Stewart, Appl. Organomet. Chem.1997, 11, 813; i) M. Bouquey,A. Soum, Macromol. Chem. Phys.2001, 202, 1232.

[6] a) W. Fink, Angew. Chem. Int. Ed.Engl.1966, 5, 760; b) G. H. Wiseman, D. R. Wheeler, D. Seyferth, Organometallics1986, 5, 146.

[7] a) Y. Blum, R. M. Laine, Organometallics1986,5, 2081; b) C. Biran, Y. D. Blum, R. Glaser, D. S. Tse, K. A. Youngdahl, R. M. Laine, J. Mol. Catal.1988, 48, 183; c) W.-D. Wang, R. Eisenberg, Organometallics1991, 10, 2222.

[8] H. Q. Liu,J. F. Harrod, Organometallics 1992,11, 822.

[9] D. Seyferth, G. H. Wiseman, C. Prud'homme, J. Am. Ceram. Soc.1983, 66, C-13.

[10] a) L. V. Interrante, K. Moraes, Q. Liu, N. Lu, A. Puerta, L. G. Sneddon, Pure Appl. Chem.2002, 74, 2111; b) R. Riedel, G.Mera, R. Hauser, A. Klonczynski, J. Ceram. Soc. Jpn.2006, 114, 425; c) G. Glatz, T. Schmalz, T. Kraus, F. Haarmann, G. Motz, R. Kempe, Chem. Eur. J.2010, 16, 4231; d) M. Zaheer, T. Schmalz,G. Motz, R. Kempe, Chem. Soc. Rev.2012, 41, 5102; e) S. K. T.Pillai, W. P. Kretschmer, C. Denner, G. Motz, M. Hund, A. Fery,M. Trebbin, S. Förster, R. Kempe, Small2013, 9, 984; f) J.K.Ewert, D. Weingarth, C. Denner, M. Friedrich, M. Zeiger, A.Schreiber, N. Jackel, V. Presser, R. Kempe, J. Mater. Chem. A2015, 3, 18906.

[11] a) D. Kummer, E. G. Rochow, Inorg. Chem.1965, 4, 1450; b) K. Feng, Y. H. Mariam, Macromolecules1991,24, 4729; c) K. Feng, P. Abrahams, Y. H Mariam, Appl. 
Organomet. Chem.1993,7,253; d) D. Su, Y.Li, F. Hou, X. Yan, J. Am. Ceram. Soc.2014, 97, 1311.

[12] I. M. Arafa, M. Al-Atrash, J. Macromol. Sci. Pure Appl. Chem.2002, A39, 1475.

[13] a) J. Hu, D. Y. Son, Macromolecules1998, 31, 8644; b) M.Veith, R.Elsässer,R.P.Krüger, Organometallics1999, 18, 656; c) G.-B. Zhang, X.-D. Fan, J. Kong, Y.-Y. Liu, M.-C. Wang, Z.-C. Qi, Macromol. Chem. Phys.2007, 208, 541.

[14] Y. Li, Y. Kawakami, Macromolecules1999, 32, 8768.

[15] a) C. Bellini, J.-F. Carpentier, S. Tobisch, Y. Sarazin, Angew. Chem. Int. Ed.2015, 54, 7679; b) C. Bellini, V. Dorcet, J.-F. Carpentier, S. Tobisch, Y. Sarazin, Chem. Eur. J.2016,22, 4564 .

[16] C. Bellini, C. Orione, J.-F. Carpentier, Y. Sarazin, Angew. Chem. Int. Ed.2016, 55, 3744 .

[17] a) L. H. Sommer, J. D. Citron, J. Org. Chem.1967, 32, 2470; b) J. F. Blandez, I. EsteveAdell, M. Alvaro, H. García, Catal. Sci. Technol.2015, 5, 2167.

[18] C. K. Toh, H. T. Poh, C. S. Lim, W. Y. Fan, J. Organomet. Chem.2012, 717, 9.

[19] E. J. Matarasso-Tchiroukhine, Chem. Soc., Chem. Commun.1990, 681.

[20] H. Q. Liu, J. F. Harrod, Can. J. Chem.1992, 70, 107.

[21] J. He, H. Q. Liu, J. F. Harrod, R. Hynes, Organometallics 1994,13, 336.

[22] L. K. Allen, R. García-Rodríguez, D. S. Wright, Dalton Trans.2015, 44, 12112.

[23] A. E. Nako, W. Chen, A. J. P. White, M. R. Crimmin, Organometallics2015, 34, 4369.

[24] a) K. Takaki, T. Kamata, Y. Miura, T. Shishido, K. Takehira, J. Org. Chem.1999, 64, 3891; b) K. Takaki, K. Komeyama, K. Takehira, Tetrahedron2003, 59, 10381; c) F. Buch, S. Harder, Organometallics2007, 26, 5132; d) W. Xie, H. Hu, C. Cui, Angew. Chem. Int. Ed.2012, 51, 11141; e) A. Pindwal, A. Ellern, A. D. Sadow, Organometallics2016, 35, 1674.

[25] J. X. Wang, A. K. Dash, J.-C. Berthet, M. Ephritikhine, M. S. Eisen, J. Organomet. Chem.2000, 49, 610 .

[26] T. Tsuchimoto, Y. Iketani, M. Sekine, Chem. Eur. J.2012, 18, 9500.

[27] S. Anga, Y. Sarazin, J.-F. Carpentier, T. K. Panda, ChemCatChem2016, 8, 1373.

[28] a) J. F. Dunne, S. R. Neal, J. Engelkemier, A. Ellern, A. D. Sadow, J. Am. Chem. Soc.2011, 133, 16782; b) M. S. Hill, D. J. Liptrot, D. J. MacDougall, M. F. Mahon, T. P. Robinson, Chem. Sci.2013, 4, 4212. 
[29] The conversions here and in the following sections are given for optimised reaction times and temperatures for reactions performed in NMR tubes. For large-scale syntheses followed to ensure complete conversion of the substrates, other conditions were used, as given in the experimental protocols. See the Supporting Information for detail.

[30] It has been shown before that $\mathbf{5}$ could be prepared in a more principled fashion by dehydrocoupling of $\mathrm{BnNHSiPh}_{2} \mathrm{NHBn}$ with $\mathrm{Ph}_{2} \mathrm{SiH}_{2}$ catalysed by $\mathrm{Ba}\left[\mathrm{N}\left(\mathrm{SiMe}_{3}\right)_{2}\right]_{2} \bullet(\mathrm{THF})_{2}$, see ref [15a]. As a test, this same reaction catalysed by $\mathbf{A}$ gave full conversion to $\mathbf{5}$ under mild conditions $\left(\left[\mathrm{Ph}_{2} \mathrm{SiH}_{2}\right]_{0} /\left[\mathrm{BnNHSiPh}{ }_{2} \mathrm{NHBn}\right]_{0} /[\mathbf{A}]_{0}=\right.$ 100:100:1, $\left[\mathrm{BnNHSiPh}{ }_{2} \mathrm{NHBn}_{0}=1.0 \mathrm{M}\right.$ in benzene, $\left.25^{\circ} \mathrm{C}, 2 \mathrm{~h}\right)$.

[31] Because of the high contents in silicon resulting in the formation of non-pyrolisable silicon carbides, the results for the analysis of carbon contents were lower than expected in a number of occasions, see the experimental section.

[32] The ${ }^{29} \mathrm{Si}$ NMR spectra for $\mathbf{3}$ and $\mathbf{4}$ are characterised by two singlet resonances of equal intensities, at $\delta_{29 S i}=-9.87$ and -13.18 ppm for $\mathbf{3}$, and at -11.19 and -15.97 ppm for 4 . A single resonance at $-11.50 \mathrm{ppm}$ is found in the ${ }^{29} \mathrm{Si}$ NMR spectrum of $\mathbf{5}$. These values fall within the typical range of ${ }^{29} \mathrm{Si}$ chemical shifts expected for aryl-substituted silazanes.

[33] a) R. A.Benkeser,H. R. Krysiak, J. Am. Chem. Soc.1954, 76, 6353; b) R. A. Benkeser, R. A. Hickner,D. I. Hoke, J. Am. Chem. Soc.1958, 80, 2279.

[34] I. Castillo, T. Don Tilley, Organometallics2001, 20, 5598.

[35] S. J. Mitton, R. McDonald, L.Turculet, Angew. Chem. Int. Ed.2009, 48, 8568.

[36] M.Onoe, K. Baba, Y. Kim, Y. Kita, M.Tobisu, N.Chatani, J. Am. Chem. Soc.2012, 134, 19477.

[37] H. Kameo, S. Ishii, H.Nakazawa, Dalton Trans.2013, 42, 4663.

[38] Y.Kanno, T.Komuro, H.Tobita, Organometallics 2015, 34, 3699.

[39] K. Itami, K. Terakawa, J.-I. Yoshida, O. Kajimoto, J. Am. Chem. Soc.2003, 125, 6058.

[40] Y.Zafrani, E.Gershonov, I. Columbus, J. Org. Chem.2007, 72, 7014.

[41] While barium amides are key reactive intermediates in Ba-catalysed $\mathrm{N}-\mathrm{H} / \mathrm{H}-\mathrm{Si} \mathrm{CDC}$ reactions, barium silyl species do not intervene in this catalytic cycle. See ref [15].

[42] The otherwise commercially available $\mathrm{Me}_{3} \operatorname{SiNHBn}\left(\mathbf{1 6}\right.$; CAS $\mathrm{n}^{\circ}$ 14856-79-2) was prepared by salt metathesis between $\mathrm{Me}_{3} \mathrm{SiH}$ and $\mathrm{BnNHLi}$, since the $\mathrm{CDC}$ of amines with hydrosilanes bearing aliphatic alkyl groups is rather sluggish, see ref [15]. 
[43] a) S. Tobisch, Chem. Eur. J.2014, 20, 8988; b) S. Tobisch, Chem. Eur. J.2015, 21, 6765 .

[44] The DFT-derived mechanistic scenario for generation of 5 from $\mathbf{4}$ in the presence of barium bis-alkyl precatalyst $\mathbf{A}$, which sees the initial rapid and quantitative conversion of the barium bis-alkyl into the barium bis-silazanyl amido compound competent of triggering $\mathbf{4} \rightarrow \mathbf{5}$ transformation to involve substrate-assisted $\beta-\mathrm{C}_{6} \mathrm{H}_{5}$ transfer onto barium as kinetically most demanding step, conforms with the observed rate law, describing a first-order dependence on the concentration of both catalyst and substrate.

[45] E. Duguet, M. Schappacher, A. Soum, J. Organomet. Chem.1993, 458, 9.

[46] W. Fink, Helv. Chim. Acta1964, 47, 498. 